\title{
ENTRE UM PASSADO PIONEIRO E UM DESTINO DE PROGRESSO: CONSTRUÇÃO DE UM PROJETO POLÍTICO- INTELECTUAL NO INTERIOR DO PARANÁ
}

Resumo: O artigo busca analisar ações político-intelectuais a partir da trajetória biográfica de Francisco Irineu Brzezinski, figura pública atuante no interior do Paraná nos anos de 1970/80. Com um corpus documental composto por entrevista, obras ensaísticas, pronunciamentos e artigos publicados na imprensa, atas, ofícios e projetos de lei produzidos pelo personagem, procuramos, a partir da teoria das elites e da história dos intelectuais, problematizar o que podemos chamar de um projeto intelectual de idealização histórica e um viés desenvolvimentista sobre as realidades de Campo Mourão e região.

Palavras-chave: Trajetórias biográficas; teoria das elites; história dos intelectuais.

\section{BETWEEN A PIONEER PAST AND A DESTINY OF PROGRESS: CONSTRUCTION OF A POLITICAL-INTELLECTUAL PROJECT IN INLAND PARANÁ}

Abstract: The article seeks to analyze political and intellectual actions from the biographical trajectory of Francisco Irineu Brzezinski, an active public figure in inland Paraná state in the years 1970-80. With a documentary corpus composed of interviews, essay works, statements and articles published in the press, minutes, letters, and bills produced by the character, we seek, based on the elite theory and the history of intellectuals, to problematize what we can call an intellectual project of historical idealization and a developmentalist bias on the realities of Campo Mourão and region.

Keywords: Biographical trajectories; elite theory; history of intellectuals.

\section{ENTRE UN PASSÉ PIONNIER ET UNE DESTINATION POUR LE PROGRÈS: CONSTRUCTION D'UN PROJET POLITICO-INTELLECTUEL À L'INTÉRIEUR DU PARANÁ}

Résumé: L'article cherche à analyser les actions politico-intellectuelles à partir de la trajectoire biographique de Francisco Irineu Brzezinski, personnage public actif à l'intérieur du Paraná dans les années 1970/80. Avec un corpus documentaire composé d'interviews, travaux d'essais, de déclarations et d'articles publiés dans la presse, de procès-verbaux, de lettres et de factures produits par le personnage, nous cherchons, sur la base de la théorie des élites et de l'histoire des

\footnotetext{
${ }^{1}$ Doutor em História pelo Programa de Pós-Graduação da Faculdade de Ciências Humanas e Sociais da Universidade Estadual Paulista Júlio de Mesquita Filho (campus Franca), na linha de pesquisa História e Cultura Política. Realizou estágio de pós-doutorado (2018-2020) junto ao Programa de Pós-Graduação Interdisciplinar Sociedade e Desenvolvimento da Universidade Estadual do Paraná (campus Campo Mourão).

${ }^{2}$ Doutor em História Cultural (UFSC). Professor do Programa de Pós-Graduação em História Pública e do Programa Interdisciplinar Sociedade e Desenvolvimento da Universidade Estadual do Paraná (Unespar/Campo Mourão).
} 
intellectuels, à problématiser ce que nous pouvons appeler un projet intellectuel d'idéalisation historique et d'un biais développementaliste sur les réalités de Campo Mourão et de la région.

Mots-clés: trajectoires biographiques; théorie de l'élite; histoire des intellectuels.

\section{ENTRE UN PASADO PIONERO Y UN DESTINO DE PROGRESO: CONSTRUCCIÓN DE UN PROYECTO POLÍTICO-INTELECTUAL EN EL INTERIOR DE PARANÁ}

Resumen: El artículo busca analizar acciones político-intelectuales basadas en la trayectoria biográfica de Francisco Irineu Brzezinski, una figura pública activa en el interior de Paraná en las décadas de 1970 y 1980. Con un corpus documental compuesto por entrevistas, ensayos, pronunciamientos y artículos publicados en la prensa, actas y proyectos de ley producidos por el personaje, buscamos, con base en la teoría de las élites y la historia de los intelectuales, problematizar lo que podemos llamar como un proyecto intelectual de idealización histórica y un sesgo desarrollista sobre las realidades de Campo Mourão y la región.

Palabras-clave: Trayectorias biográficas; teoría de las élites; historia de los intelectuales.

\section{Introdução}

Personalidades públicas e membros de elites políticas e culturais recorrentemente foram e/ou são associados a setores intelectuais. Atuações na esfera social e a produção e disseminação de interpretações sobre realidades onde tais personagens estavam/estão inseridos são algumas das características associadas ao reconhecimento enquanto figuras distintas nas sociedades.

No caso brasileiro, as relações entre letrados, homens públicos e política fomentaram consideráveis análises, substancialmente quando perpassadas pelos vínculos com o Estado e pelas construções de sentidos identitários e de pertencimento. Conexões estabelecidas entre estruturas de poder e posições sociais pareciam justificar pretensões de superioridade e de certa "missão civilizatória" (MICELI, 2001; PÉCAUT, 1990). O alcance e relevância desses representantes elitizados está atrelado igualmente às produções difundidas (sejam elas escritas ou não) e às contribuições ao estabelecimento e identificação de projetos específicos circunscritos a esses setores. Especificamente no Paraná, que trabalhamos com mais atenção no presente artigo, estudos históricos e textos literários em torno da identidade cultural e social do estado passaram a ser produzidos desde a transição do século XIX para o XX, justamente por representantes de setores considerados intelectuais e de elites (OLIVEIRA, 2009).

Assim, a partir das perspectivas concernentes à História dos Intelectuais e à Teoria das Elites, bem como ao uso da biografia como elemento de análise histórica, buscamos problematizar alguns aspectos das vivências de Francisco Irineu Brzezinski, personagem 
que construiu sua trajetória como escritor, jurista e legislador municipal e federal em algumas cidades do Paraná e em Brasília, capital federal. Para tanto, problematizamos dois elementos de sua trajetória biográfica - aqueles relacionados ao aspecto sociopolítico e ao que chamamos de projeto intelectual-literário - como um exercício analítico para compreender áreas de atuação e campos de influência de nosso personagem, bem como sua identificação enquanto uma figura relevante na construção de uma identidade de pertencimento local, sobretudo de Campo Mourão, de onde constrói sua trajetória de vida.

Nossa discussão é realizada tomando como base parte de suas obras ensaísticas, discursos e artigos publicados na imprensa, além de projetos de lei e ofícios produzidos a partir do exercício da política institucionalizada - como vereador e deputado federal -, e publicados nas décadas de 1970 e 1980 . Entendemos que explorar a trajetória de vida e as implicações das ações de membros da intelectualidade ou daqueles denominados como elites revela-se um recurso interessante na apreensão tanto das transformações históricas nas camadas sociais quanto no entendimento das lógicas de poder que permeiam as relações locais e regionais. As análises a partir da trajetória de Irineu Brzezinski são construídas em sintonia com o entendimento que a biografia, resgatada pela historiografia contemporânea do limbo da perspectiva elitista (LORIGA, 2011; AVELAR, SCHMDIT, 2018), pode se oferecer como uma perspectiva problematizadora, não acrítica, em que se leva "a sério não apenas o indivíduo em sua particularidade absoluta, mas antes seu papel em meio a um conjunto de referências e na relação que ele estabelece com os seus contemporâneos" (SCHWARCZ, 2013, p. 59).

Um aporte metodológico interessante ao exercício analítico proposto pode ser encontrado em alguns elementos da chamada teoria das elites. Partindo do pressuposto que "em toda sociedade existe uma minoria que, por várias formas, é detentora do poder, em contraposição a uma maioria que dele está privada" (BOBBIO, 1998, p. 385), a noção de elites favorece a compreensão da perdurável existência de setores minoritários que concentram preponderantes parcelas de controle político e econômico que, especialmente por suas capacidades de organização (relações de interesse), conseguem manter certa homogeneidade e continuidade no exercício do poder (MICHELS, 1982; MOSCA, 1992; PARETO, 1984). Evidenciar referidas relações de desigualdade traz à tona também a percepção de características particulares que facilitariam o ingresso e/ou permanência nesses estratos elitistas, sendo o vínculo familiar um exemplo modular. Isto é, pertencer 
a uma determinada família ou núcleo potencializaria a fixação nas estruturas de poder. Para além das origens de uma produção social com seus desdobramentos e filiações, a identificação de figuras e grupos específicos ajudaria na explicação do arranjo interno das elites, bem como de seus possíveis diálogos com outros setores.

Trazendo tais aportes para uma reflexão histórica mais regional, a atenção/preocupação com a composição de um imaginário paranaense seria mais bem organizada e dirigida décadas depois com a popularização do movimento paranista, que salientava a fundação de uma perspectiva local baseada na diferença, em um esforço direcionado à certa invenção da tradição. Acerca dessa última, segundo Hobsbawm (2008), por "tradição inventada" entende-se um conjunto de práticas, em geral reguladas, que visam inculcar valores e normas de comportamento através da repetição, implicando uma continuidade em relação ao passado.

Particularidades paranaenses como a forte presença da imigração europeia e uma propagada predestinação ao desenvolvimento seriam desenvolvidas em diferentes regiões, por iniciativa e uma política de Estado desde o século XIX, mas intensificadas nas décadas de 1940 e 1950, sob os governos de Bento Munhoz da Rocha Neto e Moisés Lupion, buscando efetivar uma identificação duradoura e uma ocupação dirigida (MARTINS, 1955; MEZZOMO, 2002; PRIORI, 2012). Tais transformações sistemáticas e reorganizações passariam pelas atuações de personagens que abarcassem esses ideais identitários, entre eles intelectuais, membros das elites e figuras públicas. Seja através de escritos, ações socioculturais ou movimentações políticas, ditos atores representaram uma parcela importante no processo de construção de um sentimento de pertencimento local ou simplesmente na realização de projetos e/ou interpretações que partissem da consideração das realidades do estado.

Nomes como o do historiador Romário Martins, do escultor João Turin e do pintor João Ghelfi se tornaram referências na disseminação do paranismo (CAMARGO, 2007; PEREIRA, 1998) e igualmente na percepção da relevância da intelectualidade e dos homens públicos na redefinição de práticas culturais, encaminhamentos políticos e conteúdos sociais no Paraná desde as primeiras décadas do século XX. Ao aplicarmos referida ideia a planos mais localizados, como em microrregiões estaduais ou municípios, é possível reconhecer personagens que impactaram nas dinâmicas políticas e socioculturais de seus respectivos espaços. 
Na região norte do estado, lócus de maior inserção de nosso personagem, o território foi marcado pela expansão da cultura cafeeira paulista e por movimentos migratórios, de maneira que o curso de efetivação de identidades locais perpassou por membros de elites (letradas ou não), que constroem discursivamente sentidos da (re)ocupação e das etapas de desenvolvimento. E é precisamente por esse ângulo que podemos analisar algumas experiências de atuações de destacados sujeitos em diversas instâncias que contribuíram ao aprofundamento das perspectivas regionais e de discursos interpretativos que, em muitos casos, são carregados simbolicamente pelo signo da predestinação histórica. Campo Mourão, como veremos, em grande medida é marcada por essa compreensão na perspectiva de nosso sujeito Francisco Irineu Brzezinski, ou simplesmente Irineu Brzezinski.

Em meio ao cenário em questão, e permeando a tradição das famílias tidas como "pioneiras", nosso personagem pode ser analisado como exemplo do empenho orientado às identificações locais e ao pressuposto destino desenvolvimentista. Irineu Brzezinski, filho de uma figura política de relevo e antigo prefeito do município, Roberto Brzezinski (1955-1959), graduado em Direito e Filosofia, foi eleito, respectivamente, pelo PTB e ARENA ao legislativo municipal de Campo Mourão em duas ocasiões: 1964-1968, assumindo a partir da condição de suplente; e 1973-1977, atuando como presidente da Câmara desde o início de 1975. Posteriormente, já na década de 1980, foi eleito deputado federal pelo PMDB, em um mandato que se estendeu de 1984 a 1987. Na Câmara Federal, votou em 1985 na candidatura de Tancredo Neves para presidência do Brasil, candidato da Aliança Democrática - que fazia oposição a Paulo Maluf, tido como candidato do regime militar -, integrou a Comissão de Defesa do Consumidor e as comissões de Cultura, de Educação, de Trabalho e de Legislação Social.

Já na carreira jurídica, além de advogar na região, prestou concurso para o Ministério Público do Paraná, atuando nas comarcas de Campo Mourão, Corbélia, Guarapuava, Palmital, Pitanga, Ubiratã, Umuarama e Curitiba. Conforme consta no verbete do CPDOC/FGV (2001), em 1993 fundou o jornal "A Notícia de Fato" e organizou o "Informativo OAB”, publicação da subseção da entidade em Campo Mourão. Em 1996 fundou a Associação de Escritores da Cidade de Campo Mourão e em 1998 foi eleito conselheiro estadual da OAB/PR para o período 1998-2000. Foi, enfim, personalidade presente em propostas e ações de impacto no contexto mourãoense, como 
a colaboração na fundação da Faculdade de Ciências e Letras de Campo Mourão (Fecilcam), hoje Universidade Estadual do Paraná (Unespar), e do Museu Histórico Municipal Deolindo Mendes Pereira, além de projetos na área de infraestrutura e desenvolvimento urbano e industrial. Através de alguns de seus escritos (livros e artigos), discursos e ações, é possível analisar a dimensão da presença intelectual e das elites no âmbito local paranaense, fundamentalmente nas esferas política e sociocultural.

\section{Campo Mourão, história local e elites}

Localizado no norte do Paraná, Campo Mourão abrigou quase concomitantemente o processo de colonização baseado em frentes de expansão demográficas e pioneiras (econômicas). Esse processo de ocupação a partir de meados do século XX foi discursivamente construindo no diapasão do progresso, da modernização e do desenvolvimento como destino inegável e expressão da inevitabilidade da história (CARVALHO; NODARI, 2008; SERRA, 1992; YOKOO, 2013).

A constituição de Campo Mourão - e de outras cidades em processo de instalação no início do século XX no interior do Paraná - se confunde com a história de personagens e famílias consideradas como "pioneiras" na ocupação dos espaços geográficos que atualmente englobam a cidade da Mesorregião Centro-Ocidental Paranaense. Antigo território da Província do Guairá, percorrido em séculos anteriores por jesuítas (século XVI), bandeirantes (XVII), membros da capitania de São Paulo (XVIII) e tropeiros (XIX), foi somente nos primeiros anos do XX que movimentos de fixação foram aplicados de maneira mais efetiva. Nesse fluxo, famílias de figuras hoje ressaltadas na história local, como José Luiz Pereira, Guilherme de Paula Xavier, Jorge Walter, Edmundo Mercer e Norberto Marcondes, teriam começado a ocupar terras, seja por incentivo estatal ou por uma presumível busca por condições oportunas de ampliação econômica pessoal (HAHN; BALLER, 2017).

Umas das perspectivas mais exploradas nas narrativas de análise e disseminação das origens mourãoenses evidencia frentes de exploração e pioneiras. Em dito entendimento, o povoamento de Campo Mourão estaria diretamente atrelado ao avanço das citadas frentes de exploração (espontâneas), com expedições oriundas de localidades próximas pretendendo estender atividades agropecuárias, e pioneiras (dirigidas), 
estruturadas a partir de políticas governamentais implementadas no início do século XX (ONOFRE; SERRA, 2005).

É claro que, para além do viés de ocupação do chamado vazio demográfico, há de se ressaltar a presença de populações indígenas que sofreram com projetos de desterritorialização nas décadas prévias à municipalização de Campo Mourão e de cidades próximas. Relações interculturais entre essas comunidades nativas e as frentes de ocupação de migrantes nacionais e estrangeiros podem ser igualmente consideradas fundamentais na (re)estruturação sociocultural da região, impactando nos usos dos espaços, nos sentidos discursivos dos movimentos de colonização e nas permanências culturais; sempre ponderando os indígenas também enquanto sujeitos históricos do processo em questão (MOTA, 2012; MOTA; NOVAK, 2008; ARRUDA, 2000).

Sob o ponto de vista memorialístico e historiográfico, as narrativas construídas tendem a exaltar determinadas personalidades, erigidas como responsáveis pelo desenvolvimento e consolidação da cidade e da região, não raras vezes marcados pelo signo do heroísmo e da predestinação histórica. Nesse sentido, mais do que a ação do Estado, a atuação de migrantes e "pioneiros" seriam determinantes para evolução da região (SANTOS JÚNIOR, 2018; VEIGA, 1999; WEBER, PAGLIARINI JUNIOR, 2019). Mencionada linha de pensamento, por um lado, revela-se significativamente parcial, concentrando uma majoritária ação de poucos personagens quase como exclusivos promotores da civilização e prosperidade; por outro, serve como amparo para pensarmos a manutenção do destaque de determinadas famílias e figuras públicas como referenciais políticos, sociais e culturais mesmo nos tempos atuais.

De formação relativamente recente, a região de Campo Mourão pode ser considerada influenciada pelo processo de expansão do norte paranaense. Sendo assim, não apenas os fluxos demográficos foram importantes na etapa de (re)ocupação territorial, mas igualmente a apreensão de uma (re)construção identitária que se voltaria às prerrogativas de desenvolvimento e progresso seria valorosa na construção da história local.

Esse fator se torna relevante para pensarmos como as primeiras comunidades da região concentraram suas próprias narrativas como fundantes de uma tradição (alicerçada no discurso de pioneirismo) e suas bases familiares como privilegiadas perante uma posterior coletividade social mais numerosa, porém dividida e desarticulada. Dessa 
consideração se desprenderiam interpretações de redes familiares se projetando de maneira amplificada e sistemática na vida política (se convertendo em importantes atores políticos), assim como nas esferas econômica, cultural e social.

As marcas simbólicas do "pioneirismo", aliadas ao início das atividades econômicas locais e da urbanização, podem ser interpretadas como propulsoras de certa estrutura de poder, de modo que o envolvimento direto em áreas-chave como a política e a economia possibilitaram uma extensa gravitação social e cultural, consolidando grupos familiares e nomes específicos que perduram até hoje em esferas representativas e de tomada de decisões. Se ponderarmos que, de fato, as elites importam (RIBEIRO; BOLOGNESI, 2008), e que suas influências são decisivas em diferentes âmbitos sociais, a reflexão acerca de seus papéis sociais desempenhados se apresenta proveitosa. Por esse ângulo:

O fundamental para o estudo das minorias que dominam uma dada comunidade seria, então, a investigação da origem social de seus membros, o modo de constituição da autoridade desse grupo, os recursos (sociais, econômicos e simbólicos) que seus membros controlam e comandam, como e em que grupos sociais os indivíduos que fazem parte desse grupo minoritário são recrutados, quais as instituições que abrigam os grupos dominantes de dada comunidade, como se desenvolve a relação desse grupo com os governados etc. As respostas a essas questões revelariam informações importantes acerca da natureza e das disposições dos indivíduos que detêm o poder político e que são responsáveis pelas decisões que afetam o destino de toda comunidade (PERISSINOTTO, 2007, p. 32).

Portanto, a identificação das bases formativas das elites locais mourãoenses, bem como da validade da pesquisa biográfica em torno de figuras públicas destacadas e atuantes, conforma um alicerce profícuo para o conhecimento e estudo da história local, aprofundando olhares sobre formas de organização social e de apreensão da realidade. Independentemente de uma hipotética relação de domínio cultural e carismático de membros das elites sobre setores tratados como subalternos, é admissível cogitar a criação/emergência de intelectuais (orgânicos) dentro das próprias fileiras elitistas e que podem exercer direção ideológica e política, além de representar os interesses de suas redes familiares.

Nesse sentido, em realidades específicas, indivíduos ou grupos tidos como "elites" dispõem, constroem e/ou administram recursos (simbólicos e materiais) que os colocam em posições vantajosas em relação aos demais setores sociais, adaptando estruturas e

Revista Escritas do Tempo - v. 3, n. 7, jan-abr/2021 - p. 211-238 
reproduzindo meios de dominação. De maneira geral, são constituídas múltiplas redes sociais e políticas que, em suas complexidades, conseguem se inserir institucionalmente - principalmente através do aparelhamento do Estado - e culturalmente, apoiadas em fontes de poder econômico e simbólico que se perpetuam no tempo mediante tramas de parentesco, por exemplo (OLIVEIRA, 2001; HEINZ, 2011).

Desse modo, vislumbrar a trajetória de vida e atuação de personagens significativos nas histórias locais pode contribuir ao entendimento de lógicas de organização social e de relacionamento entre diferentes grupos da sociedade a ser analisada, que interfeririam de maneira direta nos jogos políticos, distribuição econômica e esferas culturais envolvidas. A ponderação do intelectual enquanto criador e mediador cultural (SIRINELLI, 2003), e igualmente como ator de determinadas modalidades específicas - baseadas na noção de engajamento -, leva em consideração que tais figuras, desempenham uma função social responsável por organizar representações políticas produzindo interpretações sobre a realidade, permitindo uma análise mais ampla que pode envolver temas como a interconexão entre cultura e identidade, intervenções nas práticas sociais e a criação de espaços de interlocução.

Sendo assim, o vínculo com a produção e transmissão de ideias e visões de mundo, com discursos de legitimação da ordem social (BOBBIO, 1997; ALTAMIRANO, 2008), bem como a consideração da sociabilidade na qualidade de esforço de reunião e afirmação de identidades (AGULHON, 1991), permite uma melhor compreensão das sociedades locais e do lugar dos intelectuais nelas. No caso aqui estudado, a identificação da figura de Irineu Brzezinski e de suas ações e produções, suscita plausíveis entrelaçamentos de referenciais identitários e eixos históricos, de modo que a inserção de personagens públicos (desempenhando funções intelectuais) seja relevante nas investigações históricas e socioculturais da região.

O contexto local de atuação e produção de Irineu Brzezinski remete a uma cidade ainda em transição à urbanização, se considerarmos que na década de $197064 \%$ da população vivia em áreas rurais, e no decênio seguinte esse percentual cairia para 34\%. No campo político institucionalizado, a ARENA dominava os cargos nos poderes executivo e legislativo, substancialmente até meados da década de 1980.

O início da modernização agrícola intensificou as atividades econômicas da região, fomentando novos padrões de produção e renovadas modelagens para as 
cooperativas, ${ }^{3}$ por exemplo. A melhoria das condições sociais gradativamente acompanhava o fortalecimento do Estado enquanto agente promotor da ocupação territorial e modernização regional (SERRA, 1991), justificando também, em partes, a consagração simbólica e política das citadas figuras "pioneiras".

\section{Trajetória biográfica de Irineu Brzezinski: interfaces política e intelectual}

Inseridas em tal conjuntura, as ações e produções de Irineu Brzezinski podem ser analisadas como esforços sociopolíticos e até mesmo intelectuais em meio a um espaço que iniciava sua consolidação enquanto organização social e espaço municipalizado. Como indicado anteriormente, nosso personagem provinha de uma família já inserida na esfera pública, inclusive na política local. Seu pai havia se mudado para Campo Mourão no fim da década de 1940 e anos depois seria eleito prefeito, no pleito realizado em 1955.

Voluntário na Revolução de 1930, com atuações no setor educacional e jurídico em Mallet, Roberto Brzezinski faleceria antes de concluir seu mandato, em um trágico acidente automobilístico ocorrido na região em setembro de 1959. No exercício de seu mandato, desenvolveu projetos de desenvolvimento estrutural - com obras de relevância como a biblioteca e o estádio municipais - e políticas de apoio a proprietários rurais, muitos deles oriundos das primeiras frentes "pioneiras" de ocupação da região.

De certa forma, Irineu Brzezinski figurou-se como homem público seguindo o legado de seu pai (SANTOS JÚNIOR, 2011), sendo perceptíveis semelhanças com os programas políticos de seu progenitor. Talvez uma das particularidades, e que reforça a relevância da investigação das atuações do filho, seja a extensão de tais propósitos sociopolíticos, por vezes ultrapassando a esfera estritamente institucional e alcançando contornos de um hipotético projeto intelectual mais amplo e "ambicioso".

Como já mencionado, Irineu Brzezinski desempenhou diversas funções junto à esfera jurídica, destacando-se como advogado e promotor de justiça não somente em Campo Mourão, mas igualmente nas regiões centro-oeste e noroeste do estado. Atuante também em organizações partidárias, foi vereador do município (como suplente na

\footnotetext{
${ }^{3}$ A COAMO foi criada em 1970. Atualmente, é a maior cooperativa agroindustrial da América Latina (Cf. SINTRACOOP, 2020).
}

Revista Escritas do Tempo - v. 3, n. 7, jan-abr/2021 - p. 211-238 
legislação 1963-19694 e efetivo no mandato 1973-19775), época de considerável atividade política e presença pública de Brzezinski. Nas eleições seguintes formaria chapa (como candidato à vice-prefeito) com Getúlio Ferrari visando a prefeitura mourãoense, sendo derrotado por Augustinho Vecchi e Namir Piacentini. ${ }^{6}$ Poucos anos depois, tornouse deputado federal após as eleições de 1982, obtendo a suplência após conquistar 30.504 votos e sendo posteriormente convocado a assumir em meados de $1984 .^{7}$

Afora seu já mencionado exercício na política institucionalizada, é igualmente reconhecível sua atuação como homem das letras, elaborando artigos, textos e livros de caráter literário e histórico. ${ }^{8}$ Membro fundador tanto da Associação Mourãoense de Escritores (1996) quanto da Academia Mourãoense de Letras (2001), sua presença no campo cultural da cidade acabava por fortalecer sua condição de intelectual e referência local. Em vários de seus escritos, a valorização de elementos culturais de Campo Mourão e do Paraná sinaliza a preocupação com a consolidação de uma identidade localista e com um determinado viés histórico-interpretativo específico.

Aqui é possível problematizar alguns eventos vivenciados por Irineu Brzezinski, utilizando como aporte suas produções escritas e iniciativas sociais, na perspectiva do desempenho da função de mediação enquanto figura intelectual e do seu reconhecimento como membro de uma elite (SIRINELLI, 2003; GRYNSZPAN, 1999). Podemos, assim, explorar sua trajetória focando sua atuação no que podemos caracterizar como atividades sociopolíticas e, na sequência, nas contribuições de um projeto intelectual-literário,

\footnotetext{
4 Como candidato do Partido Trabalhista Brasileiro (PTB), Irineu Brzezinski recebeu 142 votos. Em referido pleito, 10.252 votantes elegeram 10 vereadores, sendo o mais votado Rosalino Mansueto Salvadori (Partido Democrata Cristão - PDC), com 571 votos. Assumiu o cargo em 01/06/1964, permanecendo até 30/01/1969.

5 As eleições realizadas em novembro de 1972 continham apenas candidatos da Aliança Renovadora Nacional (ARENA). Irineu Brzezinski foi o segundo candidato a vereador em votos (1.337), ficando atrás somente de Maria Enilda de Oliveira Pol (1.456). Exerceu o cargo de 31/01/1973 a 31/01/1977.

${ }^{6}$ Ambas as candidaturas estavam vinculadas à ARENA. Vecchi-Piacentini receberam 9.913 votos $(43,1 \%)$ e Ferrari-Brzezinski, 6.357 (27,6\%). As outras duas candidaturas, atreladas ao Movimento Democrático Brasileiro (MDB), não chegaram, somadas, a 6.000 votos.

${ }^{7}$ Em função das nomeações de candidatos eleitos (Maurício Fruet, Nelton Friedrich e Euclides Scalco) a cargos em secretarias estaduais do então novo governador paranaense José Richa (PMDB).

8 Entre suas produções estão os livros "A troca de casais" (1979), "A vida numa penitenciária" (1996) e "Juris interessantes: coisas extravagantes (2013)". Os três livros têm como pano de fundo experiências no campo jurídico do autor. Escreveu ainda "A futura capital" (1975), obra de pesquisa histórica e documental, influenciada pelos esforços do historiador e advogado Nelson Bittencourt Prado em "resgatar" a história local. Temos interesse, em particular, por essa obra, pois nela Irineu Brzezinski constrói algumas interpretações históricas de seu projeto intelectual, em que Campo Mourão ocuparia, mesmo que num futuro distante, um lugar estratégico no desenvolvimento do Paraná.
}

Revista Escritas do Tempo - v. 3, n. 7, jan-abr/2021 - p. 211-238 
entendidas como duas variantes articuladas que expressam elementos de sua biografia junto à sociedade mourãoense. Assim, não nos parece equivocado inserir Irineu Brzezinski em um arquétipo de representação intelectual, destacando o papel de figuras letradas em múltiplas funções e permeando esforços de construção e sedimentação de elementos locais (ALTAMIRANO, 2008; HOFMEISTER, 2004).

\section{Um projeto sociopolítico desenvolvimentista?}

Ao tratarmos das ações sociopolíticas de Irineu Brzezinski, um traço se faz evidente em várias de suas propostas e em seu discurso político: o teor "desenvolvimentista", ratificando alguns discursos de época que afirmaram que na década de 1970 ninguém seguraria o desenvolvimento de Campo Mourão (SANTOS JÚNIOR, 2018). A propósito, vale ampliar o foco de análise e ponderar que o Brasil, imerso no regime militar desde 1964, encontrava no Estado o principal criador e propagador de sentidos ufanistas da realidade nacional.

Tratava-se de montar uma maquinaria burocrática que impulsionasse e reinventasse o otimismo brasileiro, na esteira de campanhas publicitárias que insistiam no "Ninguém segura este país", "Pra frente Brasil", "Brasil, conte comigo", "Você constrói o Brasil", "Quem não vive para servir ao país, não serve para viver no Brasil", "Brasil, ame-o ou deixe-o". Isto é, "o discurso pessimista, o realista, ou o crítico do governo do momento será sempre impatriótico, já que a grandiosidade brasileira só não é garantia de um futuro promissor para quem a ignore" (FICO, 1997, p. 81; CASTRO NETTO, 2019a, 2019b). Nosso personagem mourãoense parece em sintonia com tal mentalidade patriótica.

Assim, são perceptíveis menções às necessidades de aprimorar a infraestrutura da região, de fortalecer setores industriais e/ou de consolidar a disposição urbana dela. Como evidência de tal constatação, o levantamento de ofícios, proposições e requerimentos realizados durante seus dois mandatos como vereador junto à Câmara Municipal de Campo Mourão contabiliza 144 intervenções. ${ }^{9}$ Destas, 38 podem ser associadas a medidas de infraestrutura urbana e industrial. Na maioria delas, a menção ao

\footnotetext{
9 Levantamento realizado pelos autores junto ao Arquivo Municipal da Câmara Municipal de Campo Mourão.
}

Revista Escritas do Tempo - v. 3, n. 7, jan-abr/2021 - p. 211-238 
desenvolvimento municipal e regional aparece tanto como condição quanto como objetivo a ser concretizado, conforme os exemplos destacados a seguir:

O desenvolvimento de nossa cidade é palpável [...] (CÂMARA MUNICIPAL DE CAMPO MOURÃO, 1974, p. 69);

O visível desenvolvimento do município exige e por isso apresenta-se como proposição [...] (CÂMARA MUNICIPAL DE CAMPO MOURÃO, 1974, p. 96);

[...] considerando os grandes benefícios, no sentido de progresso e desenvolvimento ao Estado do Paraná [...] (CÂMARA MUNICIPAL DE CAMPO MOURÃO, 1974, p. 165);

[...] inegavelmente contribuem com o progresso de nossa região [...] (CÂMARA MUNICIPAL DE CAMPO MOURÃO, 1974, p. 175).

Um dos focos mais dirigidos relaciona-se com a questão da industrialização de Campo Mourão e região. Demonstrando preocupação com os incentivos para as indústrias locais e o possível crescimento econômico decorrente, Irineu Brzezinski defendeu, por exemplo, a criação de uma zona industrial no município ainda em 1973:

Tendo em conta o desenvolvimento do município, várias medidas devem ser tomadas para a localização de certas áreas, e entre elas a industrial, pois que, sabese [que] para instalar indústria necessário e indispensável se faz o planejamento, afim de evitar problemas como escassez de água, vias de acesso, poluição do ar, etc. [...] (CÂMARA MUNICIPAL DE CAMPO MOURÃO, 1974, p. 74).

Além de fundos municipais com o mesmo propósito industrializante:

A nossa cidade está na fase de industrialização, indiscutivelmente, o que virá trazer grande proveito não só ao município, como à região, e para o caso há necessidade de que os poderes públicos se preocupem com o problema em todo sentido, por isso, é esta, como sugestão, para que depois de apreciada e aprovada pela Câmara Municipal, ofício seja encaminhado ao senhor chefe do executivo, para que proceda a criação do fundo municipal de industrialização, para que a verba arrecadada venha a ser revertida no plano de industrialização do município (CÂMARA MUNICIPAL DE CAMPO MOURÃO, 1974, p. 134).

Essas marcações estariam atreladas também à modernização como finalidade, em seu sentido estrutural, mas também podendo ser considerada em uma perspectiva mais ampla. Partindo da crença de Campo Mourão como "município modelo do Paraná" (CÂMARA MUNICIPAL DE CAMPO MOURÃO, 1974, p. 99 e 104) e de "um povo 
em franco desenvolvimento" (CÂMARA MUNICIPAL DE CAMPO MOURÃO, 1974, p. 99), Irineu Brzezinski parecia elucidar uma preocupação com a imagem da cidade, atribuindo a certos componentes técnicos e estéticos a importância em meio à estratégia de desenvolvimento. A título de exemplo, mencionamos:

É facilmente perceptível a ornamentação que as lâmpadas modernas tem ocasionado em diversas cidades, merecendo referência exemplificativa, a questão em nossa cidade, na parte central, motivando, então, esta, para que depois de apreciada seja aprovada, como sugestão ao senhor chefe do executivo, para que por meio do Departamento Competente providencie a substituição, de lâmpadas simples, pelas modernas, no perímetro urbano da cidade (CÂMARA MUNICIPAL DE CAMPO MOURÃO, 1974, p. 131).

Também como deputado, o ponto de vista é encontrado, por exemplo, em uma proposta de isenção de impostos para compra de equipamentos agrícolas por produtores rurais, permeando a necessidade de um caminho de modernização:

A agricultura desempenha papel importantíssimo na vida da Nação [...]. Outro fato inegável é que vivemos uma época de crescente mecanização das lavouras. [...] Estamos seguindo o caminho das nações modernas, onde a máquina substitui o homem cada vez mais nas atividades primárias. [...] Estamos certos de que esta medida muito contribuirá para facilitar a vida do nosso agricultor, num momento em que ele procura recursos modernos para aumentar a produtividade do seu trabalho, refletindo os interesses maiores do Governo e da Nação (CÂMARA DOS DEPUTADOS, 1985, n.p).

O argumento comparativo com outras administrações municipais é recorrentemente encontrado nos seus discursos, tal como um amparo a seu apelo desenvolvimentista rumo a um quadro de progresso ao qual a cidade e a região supostamente já estariam destinadas. Referida modernização passaria, da mesma forma, pela organização administrativa dos setores públicos e órgãos estatais. Nesse sentido que, na condição de parlamentar, defendeu a publicação de expedientes e a prestação de contas à população, transparecendo como possíveis medidas direcionadas à modernização organizacional - a burocracia do Estado Moderno da qual expressa Max Weber (2008) através de aprimoramento de práticas administrativas. Os ofícios a seguir ilustram a questão:

Compete também, à Câmara de Vereadores, tomar conhecimento, na qualidade de órgão fiscalizador da aplicação das leis, do número de funcionários da

Revista Escritas do Tempo - v. 3, n. 7, jan-abr/2021 - p. 211-238 
municipalidade, os seus nomes, funções e vencimentos. E, em assim sendo, não é outro o objetivo deste senão de se requerer que se oficie ao Exmo. Sr. Prefeito do Município dele se obtendo a título de esclarecimento (CÂMARA MUNICIPAL DE CAMPO MOURÃO, 1974, p. 76).

O povo necessita ter conhecimento dos trabalhos do Legislativo estando muitas vezes impossibilitado de comparecer em reuniões, havendo necessidade de maior divulgação, em virtude do que pede-se o encaminhamento de ofício, para o diretor da emissora local, a fim de informar,

a. se existe programa reservado à municipalidade, e se o mesmo é pago ou gratuito.

b. seja encaminhado expediente a esta Casa para se saber da possibilidade de serem transmitidas as reuniões da Câmara e qual o seu custo (CÂMARA MUNICIPAL DE CAMPO MOURÃO, 1974, p. 102).

A reunião de trabalhos legislativos consonantes à tal intenção de divulgação e esclarecimento de ações foi organizada em obra editada por Irineu Brzezinski com o título “Ajude a administrar Campo Mourão", lançada em 1973, quando ainda exercia o cargo de vereador. Não somente o comportamento, como a racionalização empregada pelo então parlamentar é, ao que parece, uma expressão adequada da tipificação do tipo ideal de burocracia weberiano.

Ainda a respeito desse hipotético projeto político desenvolvimentista e do constante engrandecimento da cidade, Irineu Brzezinski reforçou sua posição quando eleito presidente da Câmara Municipal para o biênio 1975/76. De acordo com a ata da sessão realizada no dia 04 de março de 1975, está registrado:

Campo Mourão se encontra numa posição de destaque em nosso estado, pelo seu progresso acelerado, contribuindo decisivamente para o engrandecimento da região. Progresso esse que se deve ao trabalho do povo mourãoense, que labuta diariamente para tal. Queremos também salientar a união existente entre o Legislativo e o Executivo, e, com a colaboração do povo, Campo Mourão vem se destacando no contexto paranaense, merecendo por tal, cuidados especiais das áreas governamentais (CÂMARA MUNICIPAL DE CAMPO MOURÃO, 1975, p. 109).

Esses elementos gerados pelo nosso personagem em torno de propostas e inserções legislativas, permitem questionar se presumível projeto "desenvolvimentista", ou até mesmo "modernizador", não seria uma herança política de seu pai Roberto Brzezinski. Por outro lado, há de ser considerada uma provável influência de linhas historiográficas e geográficas do início do século XX, que enfatizavam o poder estatal e seus agentes como promotores diretos do progresso e do desenvolvimento, além, como

Revista Escritas do Tempo - v. 3, n. 7, jan-abr/2021 - p. 211-238 
mencionamos acima, de certo alinhamento com os discursos otimistas que irradiavam da capital federal (BERNARDES, 1953; HESPANHOL, 1993; FICO, 1997; CASTRO NETTO, 2019a). Ademais, o próprio movimento paranista e seus preceitos ao redor da construção de uma identidade paranaense e da sina cosmopolita do estado, direcionada à prosperidade (MARTINS, 1995), poderiam ser uma ascendência relevante nas elaborações de Irineu Brzezinski. De todo modo, parece admissível a sua faceta vinculada ao reconhecimento da necessidade de desenvolver a cidade e a região, em vistas da concretização de um desígnio progressista.

Na observação das aludidas projeções de Irineu Brzezinski, a defesa do destaque de Campo Mourão no cenário estadual teria um ponto alto no convencimento pessoal de que deveria ser a nova capital paranaense, secundando outras cidades mais bem localizadas e estruturadas. Baseando-se em uma perspectiva geográfica e aliando-a aos esforços dos grupos "pioneiros" que conseguiram estimular o desenvolvimento local, nosso personagem explorou argumentos que justificariam a escolha de Campo Mourão como novo polo referencial do estado. A obra "A futura capital", editada em 1975, foi uma materialização do empenho do então político mourãoense na promoção do município. De acordo com o autor:

Há pouco tempo, despontaram comentários de que iam acontecer certas mudanças de capitais, com a paulista para Bauru, a do Paraná para Campo Mourão e ainda a criação do novo Estado de Iguaçu, com a capital em Cascavel. Muitos e longos estudos, chegou-se à conclusão de que entre as demais localidades, a que mais reunia condições era efetivamente Campo Mourão, sendo, então, em razão disso outorgado o título deste, como Município Modelo do Estado (BRZEZINSKI, 1975, p. 153).

Ao alegar sua colocação privilegiada no estado, com sua "posição topográfica excelente, com energia elétrica abundante, a sua produção cresce cada dia que passa" (BRZEZINSKI, 1975, p. 155), podemos compreender algumas das motivações das proposições e projetos apresentados quando na condição de vereador. Qualificar a estrutura administrativa e produtiva do município caminhava ao lado da projeção dele frente aos quadros regional e estadual, fortalecendo a argumentação discursiva estabelecida.

O entroncamento rodoviário estratégico, que proporcionaria acesso facilitado a diferentes regiões do estado, seria um complemento e também demonstração da eficácia 
operada em território mourãoense. A narrativa de Irineu Brzezinski vai ao encontro, então, da percepção da evolução local como produto da confluência entre ação "pioneira" e modernização estrutural orientada por lideranças institucionalizadas. Anos antes, em 1973, em sessão da Câmara Municipal, o então vereador já assinalava a questão: “é notícia corrente na capital do estado da possibilidade de nossa cidade ser a futura capital" (CÂMARA MUNICIPAL DE CAMPO MOURÃO, 1973, p. 34). Desse modo, a identidade mourãoense estruturada na harmonização entre natureza, corpo social e Estado convergiria a um quadro quase espontâneo de progresso e de destaque:

Recebeu esta cidade, a consideração dos integrantes da Assembleia Legislativa, em proposição examinada, por comissão, o estudo de viabilidade para ser a capital, não é mais menina, mas sim a moça elegante, sadia e robusta, de sapatos altos, independente, que pelo desenvolvimento que ostenta, desfila nas passarelas do progresso da nação, que tem tudo o que dissemos, e muito mais, e que será, mais dias ou menos dias, a Capital do Estado do Paraná (BRZEZINSKI, 1975, p. 157).

Sublinhado esse viés de Irineu Brzezinski, cabe problematizar outro elemento de inserção da figura em questão. Articulada à proposta "desenvolvimentista" exposta, a identificação de um projeto intelectual-literário direcionado a recontar a história de Campo Mourão, ao mesmo tempo que certifica o papel irrepreensível dos "pioneiros", possibilita a reflexão em torno do mote fundador e civilizacional da história mourãoense.

\section{Projeto intelectual e uma história idealizada}

O caráter multifacetado do personagem trabalhado permitiu sua colocação em diferentes áreas de ação e produção. Reconhecido por sua atuação profissional no campo jurídico (onde esteve presente por mais tempo), sua figura pública ganhou destaque nos exercícios políticos institucionalizados (como vereador e deputado federal) e também por sua identificação como intelectual e escritor dedicado à história local. Curioso notar que Irineu Brzezinski parecia se autofigurar como ator público, assentindo seu pretendido papel como liderança. Um trecho da justificativa de um projeto de lei apresentado enquanto deputado federal - para a criação do Dia do Político -, é um exemplo válido:

Revista Escritas do Tempo - v. 3, n. 7, jan-abr/2021 - p. 211-238 
Devemos de todas as formas exaltar a atividade de uma classe a que pertencemos e de que nos orgulhamos, pois a causa pública foi por nós abraçada sob o alento de sinceros propósitos de idealismo patriótico. Vultos eméritos do passado e feitos heroicos que marcaram a caminhada gloriosa da Pátria através dos tempos são evocados em datas especiais. Será difícil apontar um segmento social que não tenha o seu dia comemorativo. Por que a omissão apenas do político? (CÂMARA DOS DEPUTADOS, 1984, n.p).

Partindo dessa consideração, podemos argumentar/sugerir que nosso personagem se posicionava preconcebendo certo dever de atuar, dar voz e inclusive guiar determinados setores da sociedade que compartilhavam seus princípios. Preconcepção essa que é, normalmente, associada aos intelectuais enquanto categoria social e sujeitos históricos. Sendo assim, sob tal perspectiva intelectual, Irineu Brzezinski reforçaria sua formação e sua condição de letrado, um representante da elite local que advogava seu papel de liderança.

No âmbito sociocultural, esse papel era reforçado como membro da Academia Mourãoense de Letras (AML). Criada em 2001, mediada por ações da Associação Mourãoense de Escritores (AME) e da então Fecilcam - ambas com atuação de Irineu Brzezinski na fundação delas -, a AML partia do pressuposto de "firmar a cultura paranaense, valorizando sua literatura e oportunizando o surgimento de valores culturais mourãoenses" (ACADEMIA MOURÃOENSE DE LETRAS, s.d.). ${ }^{10}$

Fundador da cadeira número 2, teve como patrono o já aludido Nelson Bittencourt Prado, personagem igualmente interessado nos processos históricos locais e fonte de inspiração para vários de seus discursos e escritos. Para as famílias "pioneiras" e grupos da elite, a AML poderia se configurar como um holofote de legitimidade junto à interpretação de indispensabilidade da atuação dos primeiros grupos das frentes de ocupação da região em décadas anteriores. Em um paralelo com a teoria das elites, aproximar-se-ia da percepção e reconhecimento de certa eficácia política subjetiva (ALMOND; VERBA, 1989), envolvendo a relevância como ator político em cenários específicos. Ditos determinantes culturais estariam entrelaçados com valores e instituições, favorecendo o compartilhamento de atitudes políticas e a adesão de indivíduos a um sistema ou plano normativo.

10 Para mais informações consultar: Academia Mourãoense de Letras. Disponível em: <https://aml.art.br/academia/> . Acesso em: 06 abr. 2021.

Revista Escritas do Tempo - v. 3, n. 7, jan-abr/2021 - p. 211-238 
Dessa forma, considerando tais legitimidades e condutas, um dos instrumentos de interferência seria a ligação com o discurso histórico do espaço envolvido. Por meio da análise de alguns de seus direcionamentos, não seria equivocado apontar um projeto intelectual de recontar/reescrever a história de Campo Mourão. O vigor na divulgação e defesa das chamadas "frentes pioneiras" da região privilegiava a perspectiva desses personagens como fundadores e condutores de um caminho de progresso. O seu livro, "A futura capital", teve como um de seus propósitos justamente a edificação de dito prisma histórico:

Como a ocasião que nos foi proporcionada, em que pudemos manusear alguns trabalhos que foram elaborados, a respeito de diversos municípios, e principalmente em relação ao nosso estimado, progressista e querido Estado do Paraná, confessamos, sinceramente, sentimos inveja, reconhecendo o esforço inegável, daqueles que amam a sua terra, e deixam registrados dados que perduram para sempre. Apreciando a dedicação e paciência dos idealistas, vimos nascer o dever e a obrigação, de como filhos da bendita terra mourãoense, indicarmos a nossa modesta, despretensiosa e humilde contribuição, assinalando aquilo que conseguimos, graças à valiosa cooperação daqueles que entenderam o nosso propósito, auxiliando-nos no preparo desta simples reportagem.

Assim sendo, com a percepção de que nenhum valor literário possui este, mas, pura e simplesmente, para devolvermos um pouco do muito que recebemos, do lugar que fixamos residência, desde os primórdios de nossa infância, apontamos o que colhemos, para que algo sobre o chamado Município Modelo fique anotado, ao invés de pelo desinteresse ficar apagado ou reunido em mãos de poucos, que transmitem por sucessão e com o correr do tempo, se dificulte, grandemente, a sua compilação.

Veio, então, a nossa vontade em dizer alguma coisa sobre a gigantesca Campo Mourão atual, que foi lugarejo de outrora (BRZEZINSKI, 1975, p. 9).

Irineu Brzezinski enaltecia a importância dos chamados "pioneiros" como depositários de uma "memória oficial" do município e da região, indicando os feitos dessas primeiras famílias a ocuparem os territórios locais como marcos culturais alicerçantes. Ao silenciar a existência de outros segmentos sociais - como as já estabelecidas comunidades indígenas e de caboclos - , heroicizou condutas "desbravadoras" de migrantes que se deslocaram para ocupar a região. Essa perspectiva de divisas civilizatórias é mais uma vez reforçada quando proferiu seu discurso de posse como deputado federal, em agosto de 1984:

E daí a nossa posição inicial de comunicação de que temos origem no Estado do Paraná, mais especialmente na região centro-oeste, com a sua representação de liderança em Campo Mourão, que se destaca pelo trabalho, dedicação, caráter e

Revista Escritas do Tempo - v. 3, n. 7, jan-abr/2021 - p. 211-238 
personalidade de sua gente, tendo, graças à coragem e luta incessante, sua independência política assinalada no dia 10 de outubro de 1947, onde o marco da civilização foi fixado, para exemplificação de honradez e dignidade (BRZEZINSKI apud SANTOS JÚNIOR; VEIGA, 2009, p. 110).

A divulgação e glorificação de um passado demarcado pela ação "pioneira", responsável pela orientação "desenvolvimentista" na região (WEBER; PAGLIARINI JUNIOR, 2019), envolveria também o entendimento do domínio sobre a natureza, movendo o corpo social instituído rumo à prosperidade, em oposição à condição anterior de "barbárie" e atraso.

De certa maneira, a suposta pretensão de homogeneização identitária e cultural representaria a memória e os perfis históricos das elites envolvidas nos processos de criação e disseminação dessas tradições. Enquanto membro de uma elite "pioneira" e figura intelectual, Irineu Brzezinski carregou consigo essa "missão" de divulgar a história mourãoense através de sua leitura e interpretação dos fatos passados e da realidade local, mediando vozes e concepções de certos grupos sociais. Seus posicionamentos públicos a respeito da elaboração de uma obra de cunho histórico são identificáveis desde o início dos anos 1970 até a entrada no século XXI, mesmo com a publicação de "A futura capital” em 1975. Em ofício de abril de 1973, o então vereador encaminhou requerimento:

para informar à Câmara se existe a possibilidade de, às expensas do município, publicar o livro histórico de Campo Mourão, o qual já em minúcias, está praticamente preparado graças aos esforços do historiador Nelson Bittencourt Prado, cujo trabalho foi feito, quanto ao município e comarca, pelo signatário desta, inclusive com documentário fotográfico, sem qualquer despesa outra, inclusive quanto à autoria dos que elaboraram o estudo, tudo, no sentido de que a nossa vida político-administrativa-econômica, fique registrada, com a promoção sem dúvida, sob o aspecto cultural do nosso município, o que foi conseguido graças à boa vontade dos pioneiros de nossa região (CÂMARA MUNICIPAL DE CAMPO MOURÃO, 1975, p. 140). ${ }^{11}$

Décadas depois, já no século XXI, Irineu Brzezinski ainda expressaria a preocupação com a divulgação da história local. Em reunião da recém-criada AML, é exposto em ata:

\footnotetext{
${ }^{11}$ A questão foi lembrada pelo vereador em outros dois requerimentos: de 22 de maio de 1973 e de 20 de junho de 1973, ambos ressaltando a importância da "obra que é interesse da coletividade".
}

Revista Escritas do Tempo - v. 3, n. 7, jan-abr/2021 - p. 211-238 
Irineu Brzezinski fala da importância de "sonhar alto" e pede para que todas as ideias sejam registradas em ata. Sua proposta de projeto é sobre uma obra que deverá ser escrita recontando a história de Campo Mourão já que, segundo ele, há necessidade de se esclarecer alguns pontos. Diz que as atuais obras não são esclarecedoras (ACADEMIA MOURÃOENSE DE LETRAS, 2002, p. 20-21).

Constantemente mencionados, os personagens tidos como "pioneiros" pareciam ser parte central dos interlocutores de Irineu Brzezinski. Isto é, discursos, ações e projetos elaborados levavam em consideração o diálogo com esse setor da elite mourãoense; de certa forma, assegurando a posição deles na sociedade local. Em seu exercício como vereador, as propostas de homenagens a figuras encaradas como relevantes historicamente ocuparam porção significativa da sua agenda, já que estiveram presentes em 33 dos seus 144 ofícios, proposições e requerimentos. As citações a seguir exemplificam o teor enaltecedor dirigido a algumas personalidades:

Várias pessoas em nossa cidade têm contribuído para o progresso em todo sentido, merecendo algumas relevo, pelo zelo na esfera educacional, sendo caso de justiça, a posição de Dna. Leoni Prado Andrade [...] (CÂMARA MUNICIPAL DE CAMPO MOURÃO, 1974, p. 117).

[...] sejam prestadas homenagens a um homem, que na sua simplicidade, muito tem feito pelo município, sendo, inclusive o responsável pelo desenvolvimento do maior bairro de Campo Mourão, que hoje considerado como uma cidade satélite, e que orgulha Campo Mourão, que é o Jardim Lar Paraná, por isso, nada mais justo do que, de público a Câmara preste a ele uma homenagem, na pessoa do senhor Paulino Joaquim Slomp (CÂMARA MUNICIPAL DE CAMPO MOURÃO, 1974, p. 146).

[...] prestar homenagem a uma pessoa que tem oferecido seus esforços para a grandeza de nosso município, cuja cooperação tem se notado, por parte de sua família, com a presença sempre constante de uma mulher que enfrentou grandes dificuldades em nossa cidade, desde os primeiros dias de sua colonização [...] que é a Dna. Anita Albuquerque (CÂMARA MUNICIPAL DE CAMPO MOURÃO, 1974, p. 150).

[...] para que estude a possibilidade de designar uma de nossas ruas com o nome de pioneiro, o qual contribuiu inegavelmente com o desenvolvimento de nosso município, sendo considerado um dos fundadores de Campo Mourão, merecendo, sem dúvida, tal homenagem pelos seus méritos [...] que é o senhor Vani Borges de Macedo (CÂMARA MUNICIPAL DE CAMPO MOURÃO, 1974, p. 190).

A recorrência a recontar a história mourãoense foi elucidada também na sessão da Câmara Municipal em comemoração ao aniversário do município em 1976. Na ocasião, ocupando a presidência da casa, Irineu Brzezinski coordenou a entrega de títulos de 
cidadania honorária a três figuras "pioneiras" (Manoel de Andrade, José Carlos Ferreira e Antonio Teodoro de Oliveira). Convidado a saudar os homenageados, outro representante dessa elite local (Roberto Quintanilha Braga, então presidente da Associação Médica) expressou um ponto de vista bem próximo ao divulgado pelo nosso personagem:

É uma grande satisfação verificar que os homens públicos de Campo Mourão cidade tão jovem e que mal inicia sua curva ascendente de progresso, procuram reconhecer e cultuar seus pioneiros em todas as áreas de atividade humana, certos com muita razão, de que neles está o alicerce e sustentação que permitiu o desenvolvimento (CÂMARA MUNICIPAL DE CAMPO MOURÃO, 1976, p. 37).

A identificação de tal proposta pessoal de recontar e divulgar a história de Campo Mourão, sob o prisma do papel decisivo dos "pioneiros", balizaria a maioria do conjunto de ações de Irineu Brzezinski enquanto intelectual, de forma a tentar sedimentar um marco civilizatório e que garantisse a posição privilegiada desses enaltecidos setores sociais. A manutenção desse projeto, mesmo decênios depois de disseminá-lo no período de maior presença pública e atividade política, é elucidativa na compreensão do perfil de nossa figura analisada. A própria estruturação da citada AML vai ao encontro do estabelecimento de uma esfera de sociabilidade entre uma pequena elite letrada mourãoense que dava mostras - em suas primeiras formações - de se considerar depositórios da cultura e história locais. Em publicações da Academia, Irineu Brzezinski, que chegou a ser presidente da entidade entre os anos de 2004 e 2006, reforçava sua perspectiva histórica:

a pujança e o futuro promissor da cidade do Centro-Oeste do Paraná. [...] É realmente, abençoada pelo destino, a natureza reservou o seu futuro, colocando o rio Ivaí de um lado e o Piquiri de outro, destacando a cidade como líder (BRZEZINSKI, 2005, p. 14).

Bonita. Bem localizada. Líder em entroncamento rodoviário. Produtiva. Nela tudo plantado dá. Independente. Destaque Regional. Poderá ser a futura capital do Paraná. E tem mais ainda: População ordeira. Gente hospitaleira. Habitantes trabalhadores. Corajosos. Ansiosos por mais progresso e desenvolvimento. A cidade tem tudo para crescer. Tem a proteção do padroeiro, que é São José (BRZEZINSKI, 2004, p. 30). 
Nesse sentido, reescrever a história local e "refundar" a região podem ser consideradas necessidades para o sentido "pioneiro" e desenvolvimentista a ser cimentado para a Campo Mourão interpretada e divulgada por Irineu Brzezinski. Em tal missão, os destaques e homenagens às ações de membros das primeiras frentes migratórias regionais, bem como o desígnio de progresso, contribuiriam também para ressignificações socioculturais e políticas, fortalecendo a condição de elites de determinados grupos sociais e circunscrevendo campos de ação política institucionalizada.

\section{Considerações finais}

A identificação de figuras públicas com destacada atuação nos campos político e intelectual revela-se um componente valioso nas reflexões sobre realidades específicas e determinados processos históricos. Analisar produções e percursos vinculados a esses personagens pode contribuir na compreensão de elaborações político-culturais mais localizadas e igualmente da organização do tecido social ao redor de interpretações de mundo e valores partilhados.

No caso estudado, Irineu Brzezinski permeou diferentes esferas de inserção, impactando perceptivelmente os campos político e histórico-cultural locais com suas incidências sociopolíticas e seu projeto intelectual. $\mathrm{Na}$ condição de membro e representante de uma elite, desempenhou papéis importantes na condução e incorporação de princípios em meio à sociedade mourãoense, tendo a legitimidade como fator determinante na validação de suas ações.

No exercício político institucionalizado, como vereador e deputado federal, propôs projetos e estruturou iniciativas que reforçavam um espectro mais amplo de desígnio desenvolvimentista da região de Campo Mourão, diretamente associado a um marco civilizatório originado em grupos tidos como "pioneiros" e que seguem conformando um sólido setor social em âmbito local.

Personagens vinculados a essas famílias eram constantemente lembrados e homenageados como forma de sedimentação de certa interpretação da história. Tal idealização de um passado característico e intrínseco a esses setores foi do mesmo modo erigida como prioritária em um discernível projeto intelectual de Irineu Brzezinski, 
fomentado por produções escritas de cunho histórico-literário e declarações públicas na direção abordada.

Portanto, é possível afirmar que sua trajetória biográfica está amalgamada de experiências construídas a partir de suas vivências como político, escritor e advogado além do lugar simbólico como "pioneiro" -, o que parece lhe conferir legitimidade e papel intelectual perante à esfera pública. Ademais, uma constância discursiva de proximidade e serviço à "comunidade" de Campo Mourão contribuiu para reforçar seu papel social. Nas suas palavras: "Fui criado aqui no mato, estudei fora, enfrentei as dificuldades próprias da região à época. Sem ponte, passando por balsa, vendo bichos" (BRZEZINSKI apud MELLO, 2013).

Não seria o caso de tipificá-lo como um intelectual engajado, remetendo à representação de um escritor-intelectual comprometido tão presente na historiografia latino-americana a partir da década de 1960, fruto da vitória revolucionária cubana, visto que, mais do que a ponderação de um possível ideal progressista, a conotação do "compromisso" apresentava-se como uma função de ser - do autor e da obra (GILMAN, 2003). Talvez o posicionar como uma peculiar e multifacetada figura pública e intelectual possa ajudar na compreensão do sentido de suas ações e produções.

Nesse sentido, como membro da elite, sua posição foi importante nas influências exercidas nos processos políticos e na disseminação de valores para outros segmentos sociais, afetando o ordenamento da estrutura social na qual estava envolvido. Considerando-o uma figura intelectual, suas atitudes e, principalmente, seu propósito de recontar/reescrever a história de Campo Mourão foram relevantes na construção de alicerces culturais que seguem significativos na região. Diante disso, analisando as ações e produções de Irineu Brzezinski, temos a oportunidade de conhecer também pontos distintivos dos processos históricos e das peculiaridades de Campo Mourão e região, entrelaçando participação política e presença intelectual, histórica e cultural.

\section{Fontes}

ACADEMIA MOURÃOENSE DE LETRAS. Livro de atas. Campo Mourão: [s.n.], 2002.

BRZEZINSKI, Francisco Irineu. A futura capital. Curitiba: Juruá, 1975. 
BRZEZINSKI, Francisco Irineu. A nossa Campo Mourão. In: SARTORI, Rubens Luiz (org.). Compêndio da Academia Mourãoense de Letras. Campo Mourão: Editora Unespar/Fecilcam, 2004, p. 29-38.

BRZEZINSKI, Francisco Irineu. Crônicas contos e afinal o meu ponto de vista. In: OLIVEIRA, Amani Spachinski (org.). Coletânea Membros da Academia Mourãoense de Letras de Campo Mourão. Campo Mourão: Editora Sisgraf, 2005, p. 10-14.

CÂMARA DOS DEPUTADOS. Projeto de Lei n. 4053 de 1984 (do Sr. Irineu Brzezinski). Disponível em:

$\langle$ https://www.camara.leg.br/proposicoesWeb/fichadetramitacao?idProposicao=218353 >

. Acesso em: 25 jun. 2020.

CÂMARA DOS DEPUTADOS. Projeto de Lei Complementar n. 275 de 1985 (do Sr. Irineu Brzezinski). Disponível em:

<https://www.camara.leg.br/proposicoesWeb/fichadetramitacao?idProposicao=234584 > . Acesso em: 25 jun. 2020.

CÂMARA MUNICIPAL DE CAMPO MOURÃO. Livro de atas. Campo Mourão: [s.n.], 1973-1976.

CÂMARA MUNICIPAL DE CAMPO MOURÃO. Livro de proposições. Campo Mourão: [s.n.], 1973-1974.

MELLO, Nelci Veiga. Discurso - "Família Brzezinski" - Lançamento Livro: "Juris Interessantes - Coisas Extravagantes". Campo Mourão: Academia Mourãoense de Letras, 2013.

SANTOS JÚNIOR, Jair Elias dos; VEIGA, Pedro da. Oratórias históricas. Campo Mourão: Gráfica Mourão, 2009.

\section{Referências}

ABREU, Alzira Alves et al. (orgs.). Dicionário Histórico-Biográfico Brasileiro: pós1930. Rio de Janeiro: FGV, 2001.

AGULHON, Maurice. 1848: o aprendizado da República. Rio de Janeiro: Paz e Terra, 1991.

ALMOND, Gabriel; VERBA, Sidney. The civic culture: political attitudes and democracy in five nations. New York: Sage, 1989.

ALTAMIRANO, Carlos (org.). Historia de los intelectuales en América Latina. Buenos Aires: Katz Editores, Vol. I, 2008.

ARRUDA, Gilmar. Cidades e sertões: entre a história e a memória. Bauru: Edusc, 2000 . 
AVELAR, Alexandre de Sá; SCHMDIT, Benito Bisso (org.). O que pode a biografia. São Paulo: Letra e Voz, 2018.

BERNARDES, Lysia Maria Cavalcanti. O problema das "frentes pioneiras" no Estado do Paraná. Revista Brasileira de Geografia, v. 15, n. 3, p. 3-52, jul.-set. 1953.

BOBBIO, Norberto. Os intelectuais e o poder. São Paulo: Editora Unesp, 1997.

BOBBIO, Norberto. Teoria das elites. In: BOBBIO, Norberto; MATTEUCI, Nicola; PASQUINO, Gianfranco. Dicionário de política. Vol. 1. Brasília: Editora UnB, 1998, p. 385-391.

CAMARGO, Geraldo Leão Veiga de. Paranismo: arte, ideologia e relações sociais no Paraná (1853-1953). Tese (Doutorado em História). Curitiba: UFPR, 2007.

CARVALHO, Ely Bergo de; NODARI, Eunice Sueli. A civilização e a barbárie nos jornais: o imaginário do verde em cidades de fronteira agrícola no Paraná (1954/2000). Fênix, v. 5, n. 2, p. 1-19, 2008.

CASTRO NETTO, David Antônio de. Ditadura militar, propaganda e otimismo no Brasil dos anos 1970. Revista Trilhas da História, v. 8, n. 16, p. 72-96, jan./jul. 2019a.

CASTRO NETTO, David Antônio de. As agências de propaganda, o golpe e a ditadura militar brasileira. Revista Eco, v. 22, p. 112-137, 2019b.

FICO, Carlos. Reinventando o otimismo: ditadura, propaganda e imaginário social no Brasil. Rio de Janeiro: Editora Fundação Getúlio Vargas, 1997.

GILMAN, Claudia. Entre la pluma y el fusil. Debates y dilemas del escritor revolucionario en América Latina. Buenos Aires: Siglo XXI Editores, 2003.

GRYNSZPAN, Mario. Ciência política e trajetórias sociais: uma sociologia histórica da teoria das elites. Rio de Janeiro: FGV, 1999.

HAHN, Fábio André; BALLER, Leandro. Um olhar sobre a fronteira: os relatos do sertanista Edmundo Alberto Mercer. Revista Tempo, Espaço e Linguagem, v. 8, n. 1, p. 83-102, 2017.

HEINZ, Flavio M. (org.). História social de elites. São Leopoldo: Oikos, 2011. HESPANHOL, Antonio Nivaldo. A formação sócio-espacial da região de Campo Mourão e dos municípios de Ubiratã, Campina da Lagoa e Nova Cantu - PR. Boletim de Geografia, v. 11, n. 1, p. 17-28, dez. 1993.

HOBSBAWM, Eric; RANGER, Terence (orgs.). A invenção das tradições. São Paulo: Paz e Terra, 2008. 
HOFMEISTER, William. Apresentação. In: MANSILLA, Hugo et al. Os intelectuais e a política na América Latina. Rio de Janeiro: Fundação Konrad Adenauer, 2004, p. 712.

LORIGA, Sabina. O pequeno $x$ : da biografia à história. Belo Horizonte: Autêntica Editora, 2011.

MARTINS, Wilson. Um Brasil diferente: ensaio sobre o fenômeno de aculturação no Paraná. São Paulo: Anhembi, 1955.

MEZZOMO, Frank Antonio. Religião, nomos e eu-topia: práxis do catolicismo no oeste do Paraná. Cascavel: Edunioeste, 2002.

MICELI, Sergio. Intelectuais à brasileira. São Paulo, Companhia das Letras, 2001.

MICHELS, Robert. Sociologia dos partidos políticos. Brasília: Editora UnB, 1982.

MOSCA, Gaetano. La classe política. México: Fondo de Cultura Económica, 1992.

MOTA, Lúcio Tadeu. Campo Mourão: os territórios do cacique Kuaracibera dos Guarani, ou os Pahy-ke-rê dos Kaingang, ou os Campos do Mourão dos conquistadores portugueses. In: MEZZOMO, Frank Antonio; PÁTARO, Cristina Satiê de Oliveira;

HAHN, Fábio André (orgs.). Constituição de territórios paranaenses. Campo Mourão: Fecilcam, 2012, p. 105-143.

MOTA, Lúcio Tadeu; NOVAK, Éder da Silva. Os Kaingang do vale do rio Ivaí: préhistória e relações interculturais. Maringá: Eduem, 2008.

OLIVEIRA, Ricardo Costa de. O silêncio dos vencedores: genealogia, classe dominante e Estado do Paraná. Curitiba: Moinho do Verbo, 2001.

ONOFRE, Gisele Ramos; SERRA, Elpídio. A colonização de Campo Mourão - Paraná: os conflitos rurais e os primeiros mecanismos de acesso à terra. In: Anais do X Encontro de Geógrafos da América Latina, São Paulo, 2005, p. 10954-10968.

PARETO, Vilfredo. Vilfredo Pareto: sociologia. São Paulo: Ática, 1984.

PÉCAUT, Daniel. Os intelectuais e a política no Brasil: entre o povo e a nação. São Paulo: Ática, 1990.

PEREIRA, Luís Fernando Lopes. Paranismo: o Paraná inventado. Curitiba: Aos Quatro ventos, 1998.

PERISSINOTTO, Renato; CODATO, Adriano; FUKS, Mario; BRAGA, Sérgio Soares (orgs.). Quem governa? Um estudo das elites políticas do Paraná. Curitiba: Editora UFPR, 2007. 
PRIORI, Angelo et al. História do Paraná: séculos XIX e XX. Maringá: Eduem, 2012.

RIBEIRO, Ednaldo Aparecido; BOLOGNESI, Bruno. As elites paranaenses e a democracia: explorando a estrutura dimensional e os determinantes dos seus valores e atitudes políticas. Revista TOMO, ano X, n. 12, p. 83-110, 2008.

SANTOS JÚNIOR, Jair Elias dos. Roberto Brzezinski: semeador de esperança. Curitiba: Edição do autor, 2011.

SANTOS JÚNIOR, Jair Elias dos. Campo Mourão: a construção de uma cidade. Campo Mourão: Midiograf, 2018.

SCHWARCZ, Lilia Moritz. Biografia como gênero e problema. História Social, n. 24, p. 51-73, jan./jun. 2013.

SERRA, Elpídio. Processos de ocupação e a luta pela terra agrícola no Paraná. Tese (Doutorado em Geografia) - Universidade Estadual Paulista "Júlio de Mesquita Filho", Rio Claro, 1991.

SERRA, Elpídio. Os primeiros processos de ocupação da terra e a organização pioneira do espaço agrário no Paraná. Boletim de Geografia, v. 10, n. 1, p. 61-94, 1992.

SINTRACOOP. Ranking ACI confirma: COAMO é a maior cooperativa agrícola da América Latina. Publicado em 28 jan. 2020. Disponível em:

<https://www.sintracoop.com.br/?p=67035 > . Acesso em: 26 jun. 2020.

SIRINELLI, Jean-François. Os intelectuais. In: REMÓND, René (org.). Por uma história política. Rio de Janeiro: UFRJ/FGV, 2003, p. 231-269.

VEIGA, Pedro da. Campo Mourão: centro do progresso. Maringá: Bertoni, 1999.

YOKOO, Edson Noriyuki. Processo da dinâmica das frentes de ocupação territorial e da paisagem agrária na mesorregião centro-ocidental paranaense. Tese (Doutorado em Geografia) - Universidade Estadual de Maringá, Maringá, 2013.

WEBER, Astor; PAGLIARINI JUNIOR, Jorge. Narrativas sobre a ação do Estado na história da colonização de Campo Mourão (1900-1950). Fronteiras, v. 21, n. 37, p. 5880, jan./jun. 2019.

WEBER, Max. Ensaios de sociologia. Rio de Janeiro: LTC, 2008.

Artigo recebido em 18 de julho de 2020. Aceito em 19 de março de 2021.

Revista Escritas do Tempo - v. 3, n. 7, jan-abr/2021 - p. 211-238 